Hydrol. Earth Syst. Sci., 17, 1607-1618, 2013

www.hydrol-earth-syst-sci.net/17/1607/2013/

doi:10.5194/hess-17-1607-2013

(C) Author(s) 2013. CC Attribution 3.0 License.

\title{
Estimation of surface energy fluxes under complex terrain of Mt. Qomolangma over the Tibetan Plateau
}

\author{
X. Chen ${ }^{1,2}$, Z. Su${ }^{1}$, Y. Ma ${ }^{2}$, K. Yang ${ }^{2}$, and B. Wang ${ }^{2}$ \\ ${ }^{1}$ Faculty of Geo-Information Science and Earth Observation, University of Twente, Enschede, the Netherlands \\ ${ }^{2}$ Key Laboratory of Tibetan Environment Changes and Land Surface Processes, Institute of Tibetan Plateau Research, \\ Chinese Academy of Sciences, Beijing, China
}

Correspondence to: X. Chen (x.chen@utwente.nl)

Received: 10 August 2012 - Published in Hydrol. Earth Syst. Sci. Discuss.: 14 September 2012

Revised: 27 March 2013 - Accepted: 5 April 2013 - Published: 29 April 2013

\begin{abstract}
Surface solar radiation is an important parameter in surface energy balance models and in estimation of evapotranspiration. This study developed a DEM based radiation model to estimate instantaneous clear sky solar radiation for surface energy balance system to obtain accurate energy absorbed by the mountain surface. Efforts to improve spatial accuracy of satellite based surface energy budget in mountainous regions were made in this work. Based on eight scenes of Landsat TM/ETM+ (Thematic Mapper/Enhanced Thematic Mapper+) data and observations around the Qomolangma region of the Tibetan Plateau, the topographical enhanced surface energy balance system (TESEBS) was tested for deriving net radiation, ground heat flux, sensible heat flux and latent heat flux distributions over the heterogeneous land surface. The land surface energy fluxes over the study area showed a wide range in accordance with the surface features and their thermodynamic states. The model was validated by observations at QOMS/CAS site in the research area with a reasonable accuracy. The mean bias of net radiation, sensible heat flux, ground heat flux and latent heat flux is lower than $23.6 \mathrm{~W} \mathrm{~m}^{-2}$. The surface solar radiation estimated by the DEM based radiation model developed by this study has a mean bias as low as $-9.6 \mathrm{~W} \mathrm{~m}^{-2}$. TESEBS has a decreased mean bias of about $5.9 \mathrm{~W} \mathrm{~m}^{-2}$ and $3.4 \mathrm{~W} \mathrm{~m}^{-2}$ for sensible heat and latent heat flux, respectively, compared to the Surface Energy Balance System (SEBS).
\end{abstract}

\section{Introduction}

Mountainous area covers about one-fifth of the earth's continental areas (X. Yang et al., 2011). Accurate surface solar radiation estimations are essential for studies of solar energy resource, hydrological processes, and climate change. Solar radiation exerts strong control on available energy exchanges at the surface. Knowledge of the spatial distribution of solar radiation in mountainous area is therefore vital for the energy exchange process between the atmosphere and the mountain land surface. Terrain determines whether a surface receives direct radiation or if it is shaded. In zones of complex topography, variability in elevation, surface slope and aspect create strong spatial heterogeneity in solar radiation distribution, which determines air temperature, soil temperature, evapotranspiration, snow melt and land-air exchanges. The spatial and temporal distribution of surface radiation exerts a fundamental control on mass and energy exchange between air and land. The mountainous areas are often remote and inaccessible to carry out measurement of land-air interactions. The zones of complex topography therefore form interesting but little studied areas for land-air exchange studies.

Recent studies have explored approaches to estimate the regional distribution of surface heat fluxes with observational data of different satellite sensors (Ma et al., 2006, 2011; Oku et al., 2007; W. Ma et al., 2009). Remote sensing based turbulent flux algorithms can be divided into two-source (like TSEBS of Anderson et al., 2008) and single source models (like SEBS of Su, 2002). Yang et al. (2003) pointed out that a single source heat transfer model is applicable on the Tibetan plateau; SEBS was adopted here. The Surface Energy

Published by Copernicus Publications on behalf of the European Geosciences Union. 
Balance System (SEBS) developed by Su (2002) has been designed to estimate energy partitioning by using satellite and meteorological data. While most of the studies using SEBS derive surface energy balance items located at flat areas (Su et al., 2005; Yang et al., 2010), none of them consider the influence of topographical influence. With the development of satellite sensor grid resolution, when applying SEBS to the high resolution satellite dataset, the topographic influences become increasingly important. Terrain controls how much sky is visible and therefore influences incident diffuse and reflected sky radiation. Since surface solar radiation measurement is very sparse in the mountainous region, the knowledge of the terrain is thus important for the radiation balance and further for the surface energy balance in complex terrain (Tovar-Pescador et al., 2006; Aguilar et al., 2010; Long et al., 2010). The aim of this research was to combine a topographically corrected solar radiation (the amount of shortwave radiation received under clear-sky conditions) with SEBS over the Tibetan Plateau mountain area. A topographically enhanced surface energy balance system (TESEBS) was developed to generate a series of distributions of surface energy balance in a meso-scale area on the north area of Mt. Qomolangma over the Plateau. Small lakes, rivers, glacier, and surfaces with short canopies are all included in the study area (Fig. 1).

The surface energy balance analysis around Mt. Everest was studied with measurement at point scale (Zhong et al., 2009; Zou et al., 2009). The aim of this research is to upscale in situ point observations of land surface variables and land surface heat fluxes over regional scale using high resolution remote sensing data. In mountainous regions, due to the complex topography, high-resolution data are needed. Landsat TM/ETM+ sensors include optical and thermal sensors with higher image resolution. Here we use Landsat data to determine regional land surface heat fluxes around the area.

In this study, we make efforts to improve solar radiation estimation under complex terrain. The shortwave radiation reaching the surface of the earth is divided into direct, diffuse or reflected radiation. Direct radiation reaches the surface of the earth from the solar beam without interactions with particles in the atmosphere. Diffuse radiation is scattered out of the solar beam by gases and aerosols before reaching the surface. Reflected radiation is mainly reflected to the surface from surrounding terrain and is therefore important in mountainous areas. A knowledge of the values for each component is often required when considering the topographic effects on each radiation component separately (Aguilar et al., 2010). To get an accurate incoming solar radiation flux in mountainous terrain, a radiation model which considers the shading and reflecting effects of adjacent features is needed by SEBS. At each point, the direct, diffuse, and reflected solar radiations were estimated. The global radiation was obtained by adding the direct, diffuse and reflected radiation. The intention of this study is to compute the instantaneous solar radiation with the above three radiation variables for various

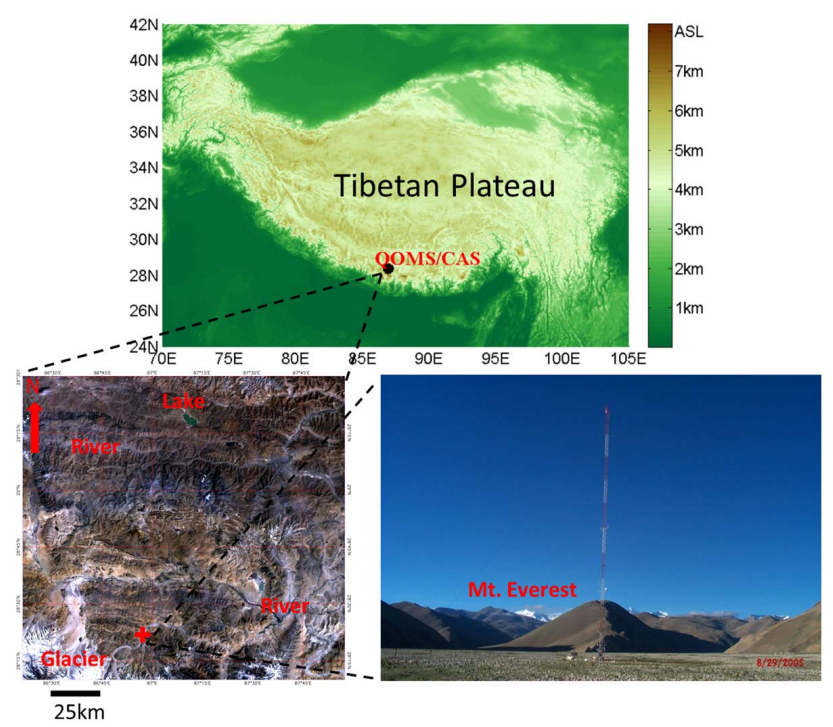

Fig. 1. The landscape of the Tibetan Plateau (top), study area (bottom-left picture, composites of TM band 2,3,4) and environment around the QOMS/CAS station (bottom-right).

slopes and azimuth terrains in order to make each component of the energy balance system more accurate.

A topography dependent incoming radiation model combined with SEBS is introduced in Sect. 2. The study area and remote sensing data preparations are included in Sect. 3. Remote sensing applications over the Qomolangma area were described in Sect. 4. The relationship between surface energy items and land cover types, and the spatial distribution of surface energy balance under complex terrain are examined in Sect. 4. Discussion and conclusions are given in Sect. 5.

\section{Model formulation}

The surface energy balance equation is written as

$R_{\mathrm{n}}=G_{0}+H+\mathrm{LE}$,

where $R_{\mathrm{n}}$ is the net radiation; $G_{0}$ is the ground heat flux; $H$ is the turbulent sensible heat flux, and LE is the turbulent latent heat flux. Latent heat flux, LE, is computed as the last item of the surface energy balance equation after derivations the of other three variables in Eq. (1).

\subsection{The instantaneous net radiation}

Net radiation is a critical input variable in the energy balance equation and the most sensitive variable in latent heat flux estimate (Zhang et al., 2005). Therefore, the accuracy of retrieved net radiation determines the accuracy of estimates of latent heat flux and ET (evapotranspiration) to some extent. For the computation of surface energy balance in complex terrain, a highly detailed surface radiation balance model is necessary. Topography is well known to alter the shortwave 
radiation balance at the surface. In order to use the surface energy balance equation over the complex topography of the Plateau, further efforts are needed to improve spatial accuracy of satellite based surface energy budgets in mountainous regions. A detailed radiation balance model is therefore required by this study. Thus here we introduce the surface radiation model as follows.

The net radiation flux is computed with the following equation:

$R_{\mathrm{n}}=(1-\alpha) \mathrm{SWD}+\mathrm{LWD}-\mathrm{LWU}$,

where $\alpha$ is the broadband albedo, SWD is downward surface shortwave radiation. LWD and LWU are downward and upward surface longwave radiation. On flat terrain and under clear-sky conditions, the downwelling shortwave radiation is nearly the same from point to point over relatively large areas and so one measurement can be taken to be representative of the entire regional area (Bastiaanssen, 2000; van der Kwast et al., 2009). However, direct measurements are rarely available to represent the shortwave radiation over most mountainous areas. Therefore, in mountainous regions a detailed solar radiation balance solution is required by surface energy balance equation. Parameterization models are often used to make predictions of individual solar radiation components under clear sky conditions (e.g., Yang et al., 2001; Liang et al., 2012). Meanwhile, the topographic effects are rarely considered. Here we employ surface radiation parameterization models and solar radiation transfer above an inclined surface to account for the impact of complex terrain, which follow the simple form of the Angstrom-Prescott model (Prescott, 1940), and its inputs (air temperature and relative humidity) are easily accessible from routine surface meteorological observations.

\subsubsection{The instantaneous downward shortwave radiation}

The surface downward shortwave (solar) radiation is divided into three parts over complex terrain: direct radiation $\left(I_{\mathrm{b}}\right)$, diffuse $\left(I_{\mathrm{d}}\right)$ and reflected $\left(I_{\mathrm{r}}\right)$ insolation.

$\mathrm{SWD}=I_{\mathrm{b}}+I_{\mathrm{d}}+I_{\mathrm{r}}$

The downward shortwave radiation varies in response to altitude, surface slope and aspect. The parameterization schemes for calculating the instantaneous solar radiation were improved by accounting for the three part variations to slope and azimuth of land surface and terrain shadow in mountainous areas. Studies have described how to use a digital elevation map dependent model to compute direct solar radiation, diffuse and reflected insolation (Kumar et al., 1997). According to the knowledge, the method used to compute distribution of downward shortwave radiation over mountainous areas is as follows:

$I_{\mathrm{b}}=I_{0} \cdot \tau_{\mathrm{c}} \cdot \cos \theta$,
$I_{\mathrm{d}}=I_{0} \tau_{\mathrm{d}}(\cos s)^{2} /(2 \sin a)$,

$I_{\mathrm{r}}=r I_{0} \tau_{\mathrm{r}}(\sin s)^{2} /(2 \sin a)$,

where $\theta$ is solar incidence angle; $a$ is the solar altitude angle; $s$ is the tilt angle of the surface (slope); $\tau_{\mathrm{c}}$ solar beam radiative transmittance; $\tau_{\mathrm{d}}$ solar diffuse radiative transmittance, and $\tau_{\mathrm{r}}$ is the reflectance transmittance; $r$ is the ground reflectance.

The applications of optical remote sensors by SEBS are limited to conditions of cloudless sky; therefore, in this paper we consider atmospheric transmittances under conditions of cloudless sky. The clear sky radiative transmittance is based on local geographical and meteorological conditions. The clear sky surface solar radiation is affected by a number of extinction processes in the atmosphere. Although Kumar et al. (1997) suggested a method for computation of $\tau_{\mathrm{c}}, \tau_{\mathrm{d}}$ and $\tau_{\mathrm{r}}$, their method did not consider the difference in Rayleigh scattering, aerosol extinction, ozone absorption, water vapor absorption and permanent gas absorption. Yang et al. (2001) developed a broadband radiative transfer model based on Leckner's (1978) spectral model. Evaluated as one of the best broadband models (Gueymard, 2003a, b), here we used the model to calculate solar beam radiative transmittance, $\tau_{\mathfrak{c}}$, and solar diffuse radiative transmittance, $\tau_{\mathrm{d}}$, under clear skies. $\tau_{\mathrm{c}}$ is computed as function of radiative transmittance due to ozone absorption, water vapour absorption, permanent gas absorption, Rayleigh scattering, and aerosol extinction, respectively. The detailed solution of $\tau_{\mathrm{c}}$ is described in Appendix A. $\tau_{\mathrm{d}}$ and $\tau_{\mathrm{r}}$ are computed with $\tau_{\mathrm{c}}$. The detail solutions for $I_{\mathrm{d}}$ and $I_{\mathrm{r}}$ are presented in Appendix B.

The influence of tilted surface on surface radiation is expressed by solar incidence angle, solar altitude angle and topographic information shown in Eqs. (4), (5), and (6). A high resolution DEM map (obtained from the US Geological Survey Earth Resources Observation and Science center) of SRTM (Shuttle Radar Topography Mission) in the region was used to calculate slope and aspect of each pixel. The slopes and aspects were then used in subsequent executions to generate solar radiations in complex mountainous areas.

\subsubsection{The instantaneous downward and upward surface longwave radiation}

It is relatively easy to estimate incoming longwave radiation under clear sky conditions. Different parameterizations for atmospheric longwave radiation were tested for clear sky periods (Brunt, 1932; König-Langlo and Augstein, 1994; Prata, 1996; Iziomon et al., 2003), but Brutsaert's (1975) method was among the best performance in the computations of incoming longwave radiation (Kimball et al., 1982; Kustas et al., 1994; Iziomon et al., 2003). Brutsaert's (1975) parameterization method is expressed as follows:

$\mathrm{LWD}=\varepsilon_{\mathrm{a}} \sigma T^{4}$, 
$\varepsilon_{\mathrm{a}}=1.24\left(\frac{e}{T}\right)^{0.14286}$,

where $\sigma$ is the Stefan-Boltzmann constant $(5.67 \times$ $\left.10^{-8} \mathrm{~W} \mathrm{~m}^{-2} \mathrm{~K}^{-4}\right)$. Air emissivity $\varepsilon_{\mathrm{a}}$ is determined by actual water vapor pressure $e(\mathrm{hPa})$ and air temperature $T(\mathrm{~K})$.

Longwave emission from different terrains was taken as isotropic here. The upward longwave radiation is computed using the Stefan-Boltzmann equation:

$\mathrm{LWU}=\varepsilon \sigma \mathrm{LST}^{4}$,

where $\varepsilon$ is the "broad-band" land surface emissivity, derived from a satellite based method referred to Chen et al. (2013). When NDVI $<0$ and $\alpha<0.47$, the pixel was taken as water surface, where $\varepsilon=0.985$; if $\alpha \geq 0.47$ the pixel was assumed as snow, where $\varepsilon=0.99$; LST is land surface temperature.

\subsection{The instantaneous soil heat flux density}

The regional ground heat flux $G_{0}$ in Eq. (1) cannot directly be mapped from satellite observations. The ground heat flux, as an indirect variable in surface energy balance, was calculated through net radiation according to a different surface dependent ratio value. The relationship between $G_{0}$ and $R_{\mathrm{n}}$ (Kustas and Daughtry, 1990) over bare soil in this area is

$G_{0}=0.315 R_{\mathrm{n}}$.

For water area (NDVI $<0$ and $\alpha<0.47$ ), we use the equation: $G_{0}=0.5 R_{\mathrm{n}}$ (Gao et al., 2011). For glacier area, $G_{0}$ is negligible according to Yang et al. (2011) and we use an equation of $G_{0}=0.05 R_{\mathrm{n}}$. The glacier is distinguished according to LST $<=273 \mathrm{~K}$. Daughtry et al. (1990) investigated that the midday $G_{0} / R_{\mathrm{n}}$ ratio is predictable from vegetation indices. For the canopy coverage area, the following equation is adopted:

$G_{0}=R_{\mathrm{n}}\left(f_{\mathrm{c}} \cdot r_{\mathrm{c}}+r_{\mathrm{s}} \cdot\left(1-f_{\mathrm{c}}\right)\right)$,

where $r_{\mathrm{s}}$ and $r_{\mathrm{c}}$ are the ratios between ground heat flux and net radiation for bare soils and surfaces with fully covered vegetation respectively. The $r_{\mathrm{s}}$ in this area is given a value of 0.315 (Kustas and Daughtry, 1990), and $r_{\mathrm{c}}$ has a value of 0.05 (Monteith, 1973). The fractional vegetation cover $f_{\mathrm{c}}$ is determined using the normalized difference vegetation index NDVI in Eq. (20).

\subsection{The instantaneous sensible heat flux density}

The sensible heat flux was computed by means of MoninObukhov similarity theory (MOST) theory with (Eq. 12):

$H=k u_{*} \rho C_{p}\left(\theta_{0}-\theta_{\mathrm{a}}\right)\left[\ln \left(\frac{z-d}{z_{0 h}}\right)-\Psi_{h}\left(\frac{z-d}{L}\right)+\Psi_{h}\left(\frac{z_{0 h}}{L}\right)\right]^{-1}$,

where $H$ is the sensible heat flux. $k$ is the von Karman constant. $u_{*}$ is the friction velocity. $\rho$ is the density of air. $C_{p}$ is specific heat for moist air. $\theta_{0}$ is the potential temperature at the surface, $\theta_{\mathrm{a}}$ is the potential air temperature at height $z, d$ is the zero plane displacement height, $\Psi_{h}$ is the stability correction functions for sensible heat transfer (Brutsaert, 1999), and $L$ is the Obukhov length. The roughness height for heat transfer $\left(z_{0 h}\right)$ or $\mathrm{kB}^{-1}$ must be accurately determined before the computation of sensible heat flux. Based on the fractional canopy coverage, Su et al. (2001) and $\mathrm{Su}$ (2002) give $\mathrm{kB}^{-1}$ as the following equation:

$\mathrm{kB}^{-1}=f_{\mathrm{c}}^{2} \cdot \mathrm{kB}_{\mathrm{c}}^{-1}+f_{\mathrm{s}} \cdot \mathrm{kB}_{\mathrm{s}}^{-1}+2 \cdot f_{\mathrm{c}} \cdot f_{\mathrm{s}} \cdot \mathrm{kB}_{m}^{-1}$,

where $f_{\mathrm{c}}$ is the fractional canopy coverage and $f_{\mathrm{s}}$ is that of soil. $\mathrm{kB}_{\mathrm{c}}^{-1}$ is the $\mathrm{kB}^{-1}$ of the canopy and $\mathrm{kB}_{\mathrm{s}}^{-1}$ is that of the bare soil. Being testified as a novel one over the Tibetan Plateau (Yang et al., 2002; Chen et al., 2010), the parameterization method of Yang et al. (2002) was introduced into $\mathrm{kB}_{\mathrm{s}}^{-1}$ equation. The soil part of $\mathrm{kB}_{\mathrm{s}}^{-1}$ in Brutsaert (1982) in Eq. (13) is revised as follows according to Chen et al. (2013):

$\mathrm{kB}_{\mathrm{s}}^{-1}=\log \left(\frac{z_{0 m}}{z_{0 h}}\right)$,
$z_{0 h}=\frac{70 \vartheta}{u_{*}} \exp \left(-\beta u_{*}^{0.5} \theta_{*}^{0.25}\right)$,

where $\vartheta$ is the kinematic viscosity of air $\left(1.5 \times 10^{-5} \mathrm{~m}^{2} \mathrm{~s}^{-1}\right)$. $\beta$ equals $7.2 \mathrm{~s}^{0.5} \mathrm{~m}^{-0.5} \mathrm{~K}^{-0.25} \cdot u_{*}$ is the surface friction velocity $\left(\mathrm{m} \mathrm{s}^{-1}\right)$, and $\theta_{*}$ is the surface friction temperature $(\mathrm{K})$. $z_{0 m}$ is momentum roughness length (m) referred to Eq. (7d) in Chen et al. (2013).

\section{Study site and data processing}

Two scenarios have been used to assess the TESEBS model. One is to use all available in situ measurements at QOMS/CAS as forcing data. The other is to use operational meteorological and satellite data. The model outputs of surface energy fluxes are then compared with flux tower measurement.

\subsection{Study area}

The Himalaya, as the south barrier of the Plateau with a large area of high mountains pierces directly to the middle troposphere of earth; consequently, it has great influence on the weather and climate of the region (Ye and Gao, 1979; Gao, 1981; Bollasina and Benedict, 2004; Ueno et al., 2008; Zhou et al., 2008; Zhong et al., 2009; Zou et al., 2009). The Himalaya exerts profound thermal and dynamical influence on atmospheric circulation (Bollasina and Benedict, 2004). The Himalaya mountains provide the water sources for the Indus, Ganges, and Brahmaputra rivers, which supply water to billions of people in Asia (Immerzeel et al., 2010). Considering the importance of the Asian monsoon (Boos and Kuang, 2010), Bollasina and Benedict (2004) 
pointed out that land-atmosphere interactions over Himalaya requires particular attention. The study was conducted in $28^{\circ} 0^{\prime} 42^{\prime \prime} \mathrm{N}$ to $29^{\circ} 0^{\prime} 54.9^{\prime \prime} \mathrm{N}$ and $86^{\circ} 9^{\prime} 5^{\prime \prime} \mathrm{E}$ to $87^{\circ} 1^{\prime} 42.8^{\prime \prime} \mathrm{E}$, located around QOMS/CAS station (Fig. 1), a comprehensive observation and research station on the north slope of Himalaya. Elevation in the study area changes between 3700 to $7107 \mathrm{~m}$. This region has been chosen because it is representative of a high-alpine environment and because of the glaciers, lakes, rivers, and short canopies present in this area (see bottom left picture of Fig. 1).

\subsection{Field measurements}

The Qomolangma Station for Atmospheric and Environmental Observation and Research, Chinese Academy of Sciences (QOMS/CAS) is located at $28^{\circ} 21.63^{\prime} \mathrm{N}, 86^{\circ} 56.93^{\prime} \mathrm{E}$, with an elevation of $4276 \mathrm{~m}$, and $30 \mathrm{~km}$ away from Mount Everest. It was established by the Institute of Tibetan Plateau Research (ITP), the Chinese Academy of Sciences (Ma et al., 2008). The dataset of the QOMS/CAS station consist of surface radiation budget components (CNR-1, Kipp \& Zonen), vertical profiles of air temperature, humidity, wind speed and direction (MILOS520, Vaisala), turbulent fluxes measured by eddy correlation technique. Sensors of wind speed, wind direction, air temperature, and relative humidity at five levels $(1.0,2.0,4.0,10.0$, and $20.0 \mathrm{~m})$ are installed on a $40 \mathrm{~m}$ p.b.l. tower. The soil temperature was measured at depths of 0 , 10, 20, 40, 80 and $160 \mathrm{~cm}$. The soil moisture content was measured at depths of 10,20 , and $30 \mathrm{~cm}$. The soil heat flux was measured using soil heat flux plates (HFP01) buried at a depth of $10 \mathrm{~cm}$. The soil heat flux at the surface is calculated by adding the measured flux at $10 \mathrm{~cm}$ depth to the energy stored in the layer above the heat flux plates (Chen et al., 2012). An open path eddy covariance turbulent measurement system (CSAT3, Campbell; LI 7500, Licor) is set up at $3.5 \mathrm{~m}$ height. The high frequency turbulent data are processed by TK2 software (Mauder and Foken, 2004) to control the quality of every half-hour flux. Calibrations are also done in the process. TK2 also produces a quality level of turbulent fluxes with the definition of the quality level given by Rebmann et al. (2005) divided into 1-5 levels. The high quality fluxes (quality level $<=3$ ) were used in this study.

For all fluxes in this paper, the same sign convention applies: fluxes transporting energy towards the surface are negative, and fluxes transporting energy away from the surface are positive.

\subsection{Local-scale evaluation}

Standard meteorological forcing data at QOMS/CAS, including wind velocity, vapor pressure, air temperature, and atmospheric pressure, were used to run the TESEBS model. Land surface temperature is derived from measured upward longwave radiation. A constant emissivity of 0.97 is assigned to estimate the surface temperature. Time series comparison of the model output and observations show that TESEBS correctly interprets variability and is capable of accurately representing the temporal development of surface energy balance items at the local scale (Chen et al., 2013).

The accuracy of the model was evaluated using mean bias (MB) and root mean square error (RMSE). These statistical indicators are defined as

$\mathrm{RMSE}=\sqrt{\frac{\sum_{i=1}^{N}\left(x_{i}-\mathrm{obs}_{i}\right)^{2}}{N}}$

$\mathrm{MB}=\frac{\sum_{i=1}^{N}\left(\mathrm{obs}_{i}-x_{i}\right)}{N}$,

where $x_{i}$ stands for simulations of TESEBS. obs $i$ stands for observations, and $N$ is the sample number. There were 4616 data points with a data quality level $<=3$ used to evaluate TESEBS in Fig. 2. Linear regression between modeled and measured values was also computed. The slope value $(=1.01)$ in Fig. 2 demonstrate that TESEBS provides a good estimation of sensible heat flux with the new $\mathrm{kB}^{-1}$ equations. The correlation coefficient $R$ is as high as 0.91 , with $\mathrm{MB}=-7.3 \mathrm{~W} \mathrm{~m}^{-2}$, and $\mathrm{RMSE}=41.76 \mathrm{~W} \mathrm{~m}^{-2}$.

\subsection{Remote sensing data preparation}

To capture the heterogeneity of the land surface over the domain, high-resolution satellite data are required. The Landsat TM/ETM+ data can provide high-resolution information on the land surface temperature, land cover classification, albedo, and the NDVI. Eight scenes of Landsat TM/ETM+ datasets were collected on 10 March 2008, 26 March 2008, 11 April 2008, 29 May 2008, 2 September 2008, 20 October 2008, 21 November 2008, and 9 April 2010 with cloudless skies. The fraction of cloud cover is not more than $3 \%$ on these days. In mountainous areas, topography also strongly influence the signal recorded by space-borne optical sensors. The topographic influence on the satellite received signal were eliminated by the method of Richter et al. (2009). The reflectivity for each band $\left(\rho_{\lambda}\right)$ is calculated as

$\rho_{\lambda}=\frac{\pi L_{\lambda}}{\operatorname{ESUN}_{\lambda} d_{\mathrm{r}} \cos \theta / \cos s}$,

where $L_{\lambda}$ is the spectral radiance for each band. $\operatorname{ESUN}_{\lambda}$ is the mean solar exo-atmospheric irradiance for each band. $\theta$ is solar incidence angle. $s$ is the surface slope. The solar exo-atmospheric irradiance for TM and ETM+1, 2, 3, 4, 5, 7 band in Markham and Barker (1987) and Chander and Markham (2003) were used separately. $\theta$ is the solar zenith angle (from nadir), and $d_{\mathrm{r}}$ is the inverse squared relative Earth-Sun distance. The surface albedo $(\alpha)$ for shortwave radiation is retrieved from converting narrowband to 


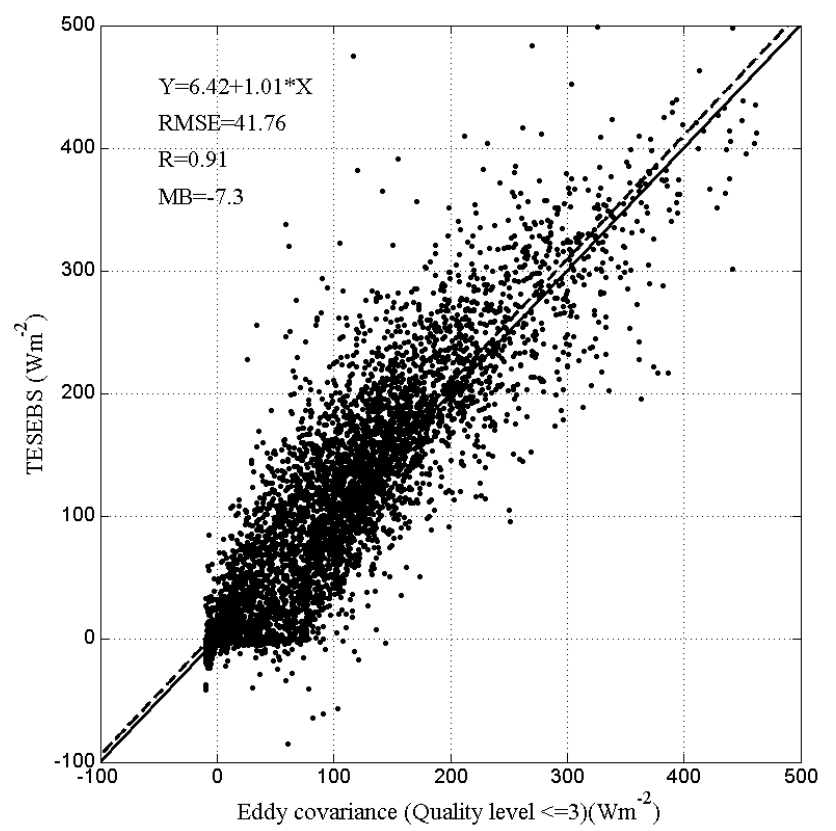

Fig. 2. Evaluation of TESEBS based on the point sensible heat flux data of high quality (with quality level $<=3$ ) in 2007 at QOMS/CAS station. Scatter plot of sensible heat flux $(H$, unit of $\mathrm{W} \mathrm{m}^{-2}$ ) between the measurements of eddy covariance (ED) and outputs of TESEBS. The thick line is $1: 1$ line. The linear fitting line is dashed line. Root mean square error (RMSE). Correlation coefficient $(R)$. Mean bias (MB).

broadband planetary reflectivity which is obtained as the total sum of the different narrow-band reflectivity according to weights for each band. The weights for the different bands are given by Teixeira (2010). Broadband shortwave surface albedo was calculated from the normalized reflection values of channels 1, 2, 3, 4, 5 and 7, using the following equation:

$$
\begin{aligned}
\alpha & =0.293 \cdot \rho_{1}+0.274 \cdot \rho_{2}+0.233 \cdot \rho_{3}+0.157 \cdot \rho_{4} \\
& +0.033 \cdot \rho_{5}+0.011 \cdot \rho_{7},
\end{aligned}
$$

where $\rho_{1}-\rho_{7}$ are the reflectivity for band 1 to 7 . The spectral radiance of band 6 is converted into a brightness temperature applicable at the top of the atmosphere by inversion of Plank's law (Teixeira, 2010). The LST is calculated by monowindow algorithm (Qin et al., 2001; Sobrino et al., 2004). The NDVI is computed as the ratio of the differences in reflectivities for the near-infrared band $\left(\rho_{4}\right)$ and the red band $\left(\rho_{3}\right)$ to their sum. The vegetation fractional coverage is estimated using formulation:

$f_{\mathrm{c}}=\frac{\operatorname{NDVI}(x, y)-\mathrm{NDVI}_{\min }}{\mathrm{NDVI}_{\max }-\mathrm{NDVI}_{\min }}$.

The value of NDVI $I_{\min }$ and $\mathrm{NDVI}_{\max }$ is about 0.2 and 0.5 (Sobrino et al., 2004). In the case of NDVI $<0.2, f_{\mathrm{c}}=0$. The broad band emissivity $\varepsilon$ is used to calculate total longwave radiation emission from the surface. This broadband
Table 1. The comparison between TESEBS and SEBS statistical variables.

\begin{tabular}{llrr}
\hline & & TESEBS & SEBS \\
\hline Sensible heat flux & RMSE & 31.1 & 34.6 \\
$\left(\mathrm{~W} \mathrm{~m}^{-2}\right)$ & MB & -15.8 & -21.7 \\
Latent heat flux & RMSE & 25.0 & 25.1 \\
$\left(\mathrm{~W} \mathrm{~m}^{-2}\right)$ & MB & -6.8 & -10.2 \\
\hline
\end{tabular}

emissivity was calculated from the NDVI according to the method of Sobrino et al. (2004). To maintain a spatial consistency, NDVI, albedo and other data were interpolated to corresponding thermal infrared band using a linear technique.

\subsection{Weather data}

To compute surface fluxes over the area of one satellite image, the spatial distribution of meteorological data (air temperature, atmospheric pressure, relative humidity etc.) at PBL height or near-surface height at satellite pixel scale is required. The spatial interpolation method is often used to get these meteorological data from meteorological stations or atmospheric reanalysis data (Ma et al., 2006; Oku et al., 2007; McVicar et al., 2007). Xie et al. (2007) pointed out that meteorological elements above Mt. Everest coincided with measurements at a meteorological station $60 \mathrm{~km}$ away. Then we assume the meteorological measurement at QOMS/CAS station can represent the synoptic situation of our research area. Air temperature for each grid cell was adjusted with respect to elevation, assuming a standard air temperature lapse rate of $6 \mathrm{~K} \mathrm{~km}^{-1}$ (Chen et al., 2007). Atmospheric boundary layer height of $600 \mathrm{~m}$ is used according to the results of Y. Ma et al. (2009). Due to the elevation changes from 4000 to higher than $8000 \mathrm{~m}$, the corresponding surface pressure changes significantly. Thus the surface pressure is estimated by

$p_{\mathrm{s}}=p_{0} \exp (-z / 8430)$

where $p_{0}=101325 \mathrm{~Pa}, z$ is DEM data in a unit of $\mathrm{m}$.

\section{Evaluations of TM/ETM+ based TESEBS results}

Instantaneous surface energy balance items at the satellite overpass time are highly dependent on the estimation of key variables, namely, land surface temperature, albedo, downward and upward shortwave/longwave radiation, etc. Hence, we evaluate these variables by comparison with sitespecific ground-based measurements (Fig. 3). The correlation coefficient of downward shortwave radiation (SWD) between TESEBS simulated and measured by radiometers is as high as 0.99 , with $\mathrm{MB}$ of $-9.62 \mathrm{~W} \mathrm{~m}^{-2}$ and RMSE of $45.4 \mathrm{~W} \mathrm{~m}^{-2}$. The LST has a mean bias of $1.48 \mathrm{~K}$ with a high $R$ value. The albedo derived from TM/ETM+ is a little bit lower than the in situ true values. The SWU of TESEBS 

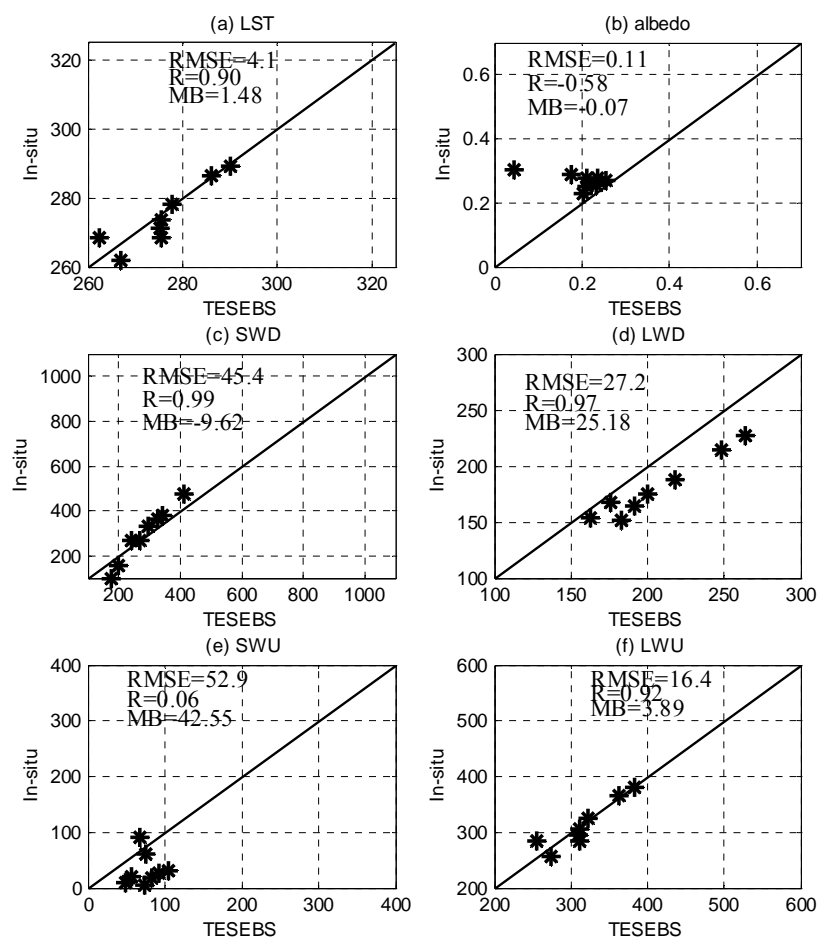

Fig. 3. Comparison of derived results with field measurements for the (a) land surface temperature (LST, unit K), (b) albedo, (c) downward shortwave radiation ( $\mathrm{SWD}$, unit $\mathrm{W} \mathrm{m}^{-2}$ ), (d) downward longwave radiation (LWD, unit $\mathrm{W} \mathrm{m}^{-2}$ ), (e) upward shortwave radiation (SWU, unit $\mathrm{W} \mathrm{m}^{-2}$ ), (f) upward longwave radiation (LWU, unit $\mathrm{W} \mathrm{m}^{-2}$ ).

have a mean value of $42.55 \mathrm{~W} \mathrm{~m}^{-2}$ higher than the observation. The final surface energy balance items were also evaluated with in situ measurement (Fig. 4). The MB values of $R_{\mathrm{n}}, H, G_{0}$ and LE is about $-23.6,-15.8,7.7$ and $-6.8 \mathrm{~W} \mathrm{~m}^{-2}$, respectively. Overall, the values derived from TM/ETM+ by TESEBS agree well with ground measurements. The comparison of TESEBS and SEBS statistical variables were listed in Table 1. Both RMSE and MB of TESEB are lower than SEBS, which shows the better performance of TESEBS.

Figure 5 shows the distribution maps $(1605 \times 1882$ pixels) of each surface energy balance item based on TM remote sensing data obtained on 9 April 2010. The overpass time is 10:32 LT (local time), the sun azimuth angle is 127.2 degree, and the sun elevation is 58.15 degree. To maintain consistency in spatial resolution, the remote sensing data of band $1,2,3,4,5,7$ were interpolated to $120 \mathrm{~m} \times 120 \mathrm{~m}$. The experimental area presents extreme variability characterized not only by steep slopes and altitude variations of thousands of meters, but also by a variety of land surfaces such as grassy marshland, several small rivers and lakes, bare soil and glaciers. Therefore, these derived parameters show a wide range due to the strong contrast of surface features. Due to low albedo of the water surface, the net radiation and
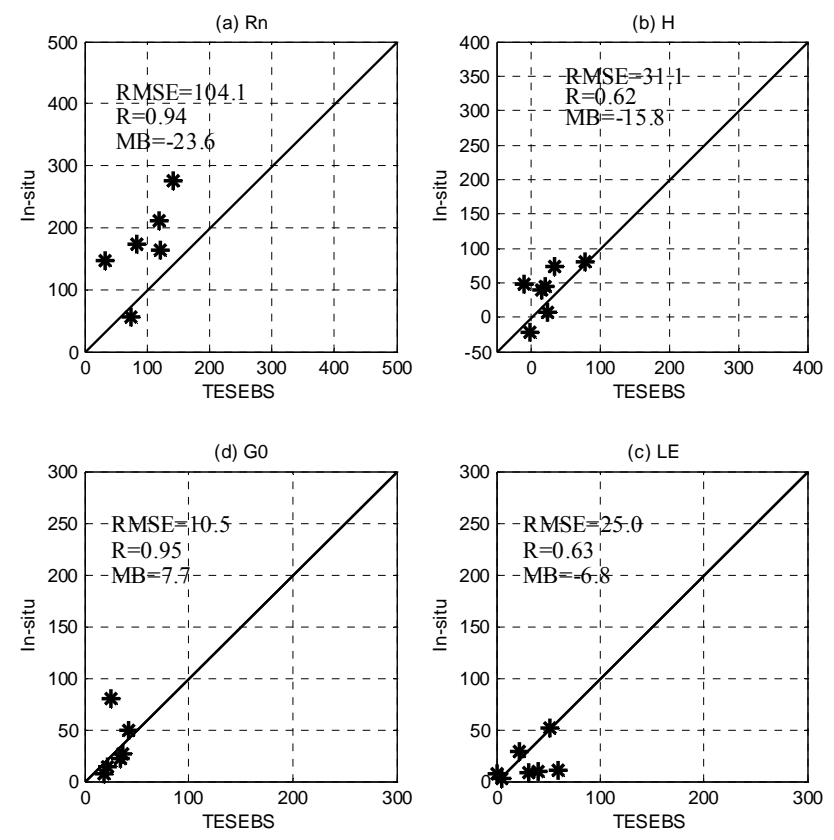

Fig. 4. Comparison of derived results with field measurements for the (a) net radiation $\left(R_{\mathrm{n}}\right.$, unit $\left.\mathrm{W} \mathrm{m}^{-2}\right)$, (b) sensible heat flux $(H$, unit $\left.\mathrm{W} \mathrm{m}^{-2}\right)$, (c) ground heat flux $\left(G_{0}\right.$, unit $\left.\mathrm{W} \mathrm{m}^{-2}\right)$, (d) latent heat flux (LE, unit $\mathrm{W} \mathrm{m}^{-2}$ ).

ground heat fluxes over the small lakes are relatively higher than in other places (Fig. 5c, d), and the corresponding sensible heat flux is lower than in other places around the bodies of water, while the latent heat flux is higher (Fig. 5a). The sensible heat flux over the glacier area is dominated by negative values. Slopes which are exposed to the East consequently have a higher net radiation and sensible heat flux than slopes with an exposition to the West.

The processes and mechanisms of energy and mass transfers become complicated under the complex terrain due to the substantial differences in radiation availability caused by various slopes and azimuths of surfaces. The surface net radiation in the region changes from -155 to $461.5 \mathrm{~W} \mathrm{~m}^{-2}$, sensible heat flux from -25.2 to $265.6 \mathrm{~W} \mathrm{~m}^{-2}$, and latent heat flux from -4.5 to $257.9 \mathrm{~W} \mathrm{~m}^{-2}$. The surface flux maps reflect distinct mechanisms of energy partition and water evaporation of various land cover types, showing differences in the spatial distribution pattern of surface turbulent heating.

West facing slopes are receiving only about half of the shortwave radiation of the eastern slopes (Fig. 7a). Such variations would surely have a significant effect on the heat budget of different places, thus influencing latent and sensible heat fluxes. It can be seen that the values in the region present a huge difference visible in the distributed values of the variable cell by cell, but also noticeable was the wide range of global values in the region, when topographic factors are taken into account, as shown by the maximum, minimum values. The spatial gradient in each part of solar radiation 

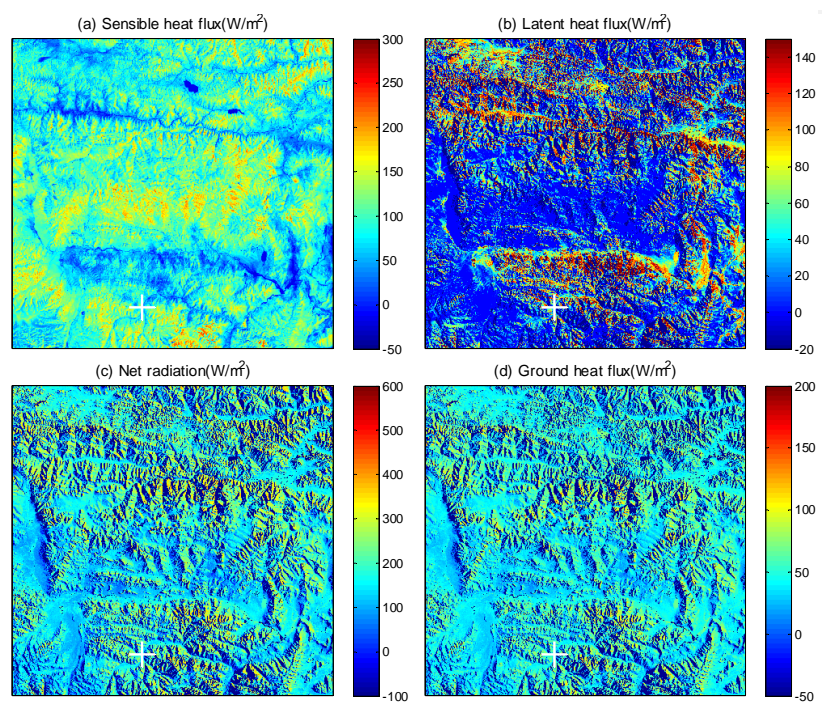

Fig. 5. Distribution of each surface energy balance item over the study area of Fig. 1b at 10:30 LT on 9 April 2010, the cross line is the location of the station. The geographical information is the same as bottom-left picture of Fig. 1.

is evident (Fig. 6). It can be seen that the locations receiving more radiation are those in the highest part of the region, with an east-facing orientation that remains unobstructed during the hours of satellite pass over. While the west-facing slopes which are shaded by the terrain at the satellite pass over time receive a relative low solar beam radiation (Fig. 6b), and a relative high diffuse radiation (Fig. 6c). The surface energy balance has the greatest influence on environmental processes, especially if snow is present. Over the snow covered glacier area on the bottom left corner of the map (Fig. 6d), the reflected solar radiation can be around $100 \mathrm{~W} \mathrm{~m}^{-2}$, which is significant compared to low values of other surface energy variables over there. This also demonstrate that the glacier topography does play a fundamental role in determining the surface energy balance (Arnold et al., 2006).

\section{Discussion and conclusions}

Dealing with regional land surface heat fluxes over heterogeneous landscapes is not an easy job. In order to analyze the interactions between the land surface around Mt. Qomolangma and the atmosphere above it, a Topographical Enhanced Surface Energy Balance System (TESEBS) was developed to upscale energy and turbulent heat fluxes from point to a meso-scale. When using high resolution satellite data over mountainous areas to get the surface energy balance items, the terrains effects must be considered. In this study, a radiation parameterization scheme for grid topography accounting for shading, and terrain reflections is used to get the surface radiation and energy balance system. DEM information was used to characterize the topographic role
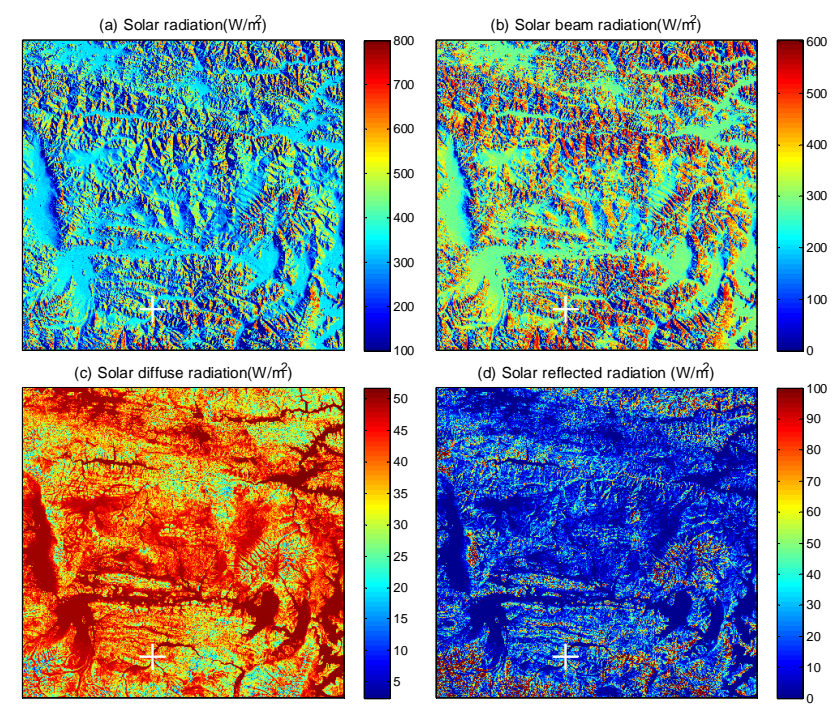

Fig. 6. Distribution of each surface solar radiation item over the study area of Fig. 1b at 10:30 LT on 9 April 2010, the cross shows the location of the station. The geographical information is the same as bottom-left picture of Fig. 1.

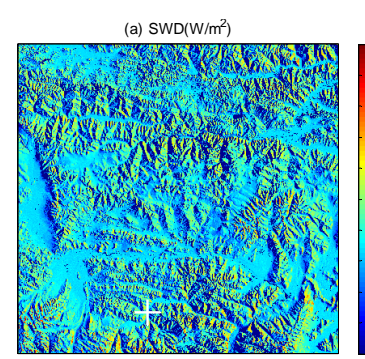

(c) $\operatorname{LWD}\left(\mathrm{W} / \mathrm{m}^{2}\right)$

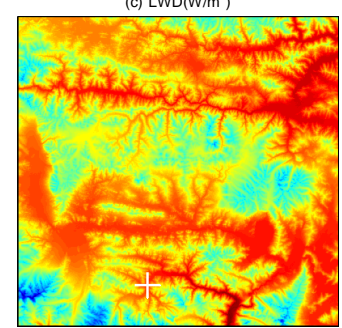

Fig. 7. Distribution of each surface radiation balance item over the study area of Fig. 1b at 10:30 LT on 9 April 2010, the cross line is the location of the station, SWD and SWU are downward and upward surface shortwave radiation. LWD and LWU are downward and upward surface longwave radiation. The geographical information is the same as bottom-left picture of Fig. 1.

in the spatial distribution of surface energy balance items in Qomolangma region's complex topography. Each radiative flux is parameterized individually as a function of slope, sun elevation angle, and albedo. We quantify the topographic impacts on each individual shortwave radiation (solar beam, diffuse and reflected radiation) with real topographies. Variations in atmospheric transmissivity resulting from actual 
column water vapor, ozone, and aerosol have been considered in our clear-sky satellite applications.

TESEBS was evaluated from site point and a regional scale. Firstly TESEBS was forced by a long time meteorological observation data at point scale. The performance of TESEBS has been evaluated by comparisons between its output fluxes and a high quality dataset of observed turbulent fluxes. Then TESEBS was expanded to a regional scale, where glaciers, bare soil and small lakes all present. It is difficult to get spatial distributions of meteorological inputs, hereby we spatialized the meteorological measurements at the station to present synoptic situation over the complex region. The distributions of surface energy balance correspond well with the land surface class. The significant incidence of topography on the values of surface energy balance throughout the region has been demonstrated by the proposed topographic solar radiation algorithm. Results indicate that surface flux predictions from TESEBS perform well at local scales on a flat terrain, when assessed against in situ flux measurements derived from eddy covariance approaches, and provides realistic outputs at regional scale for more complex topography. Due to lack of measurement on different aspect and slopes, it is impossible to do fully evaluations for this complex topography.

This work helps us to analyze the possibility and suitability of TESEBS to model surface turbulent heat flux over typical land covers of the Plateau by remote sensing technique. The performance of TESEBS over the glaciers also makes it possible to study the energy balance of the snowpack, and validate snowmelt runoff models in the future. Opportunities also exist for improving the performance of both models via data assimilation and model calibration techniques that integrate remote sensing based surface energy flux predictions.

However, the topography effects on the roughness length still remain a blank area at present. Advection could be formed under complex terrain, which may complicate the energy balance at point scale. In the future, further validation of the parameterization method needs to be made over the Plateau water surface and other land covers.

\section{Appendix A}

\section{Direct radiation}

Due to scattering processes by molecules (Rayleigh scattering) and by aerosols (Mie scattering) as well as due to absorption processes by different components of the atmosphere only a fraction of solar radiation is received as global radiation at the surface. Simple broadband transmittance functions for each atmospheric constituent are therefore commonly applied to solar radiation in order to obtain the spectrally integrated direct and diffuse sky radiation components. Solar radiation is attenuated as it passes through the atmosphere and, in a simplified case:
$I_{0}=S_{0} \cdot\left(1+0.0344 \cdot \cos \left(\frac{2 \pi \cdot \text { doy }}{365}\right)\right) \cdot \sin a$,

where $S_{0}\left(1367 \mathrm{~W} \mathrm{~m}^{-2}\right)$ is solar constant; doy is day of the year; $a$ is the solar altitude angle. The equation accounts for variation in the solar irradiance at the top of the atmosphere throughout the year.

The last stage is to calculate the solar radiation on a tilted surface. Incident global radiation is defined as the sum of incident direct (beam) radiation $\left(I_{\mathrm{b}}\right)$, incident diffuse sky radiation $\left(I_{\mathrm{d}}\right)$ due to scattering processes in the atmosphere, and incident radiation received from the surrounding terrain due to reflections $\left(I_{\mathrm{r}}\right)$.

$$
\begin{aligned}
I_{\mathrm{b}} & =I_{0} \cdot \tau_{\mathrm{c}} \cdot \cos \theta, \\
\tau_{\mathrm{c}} & \approx \max \left(0, \tau_{\mathrm{oz}} \cdot \tau_{\mathrm{w}} \cdot \tau_{\mathrm{g}} \cdot \tau_{\mathrm{r}} \cdot \tau_{\mathrm{a}}-0.013\right), \\
\tau_{\mathrm{oz}} & =\exp \left(-0.0365(m \cdot l)^{0.7136}\right), \\
\tau_{\mathrm{w}} & =\min [1,0.909-0.036 \cdot \ln (m \cdot w)], \\
\tau_{\mathrm{g}} & =\exp \left(-0.0117 m_{\mathrm{c}}^{0.3139}\right), \\
\tau_{\mathrm{r}} & =\exp \left[-0.008735 m_{\mathrm{c}}\right. \\
& \left.\left(0.547+0.014 m_{\mathrm{c}}-0.0038 m_{\mathrm{c}}{ }^{2}+4.6 \times 10^{-6} m_{\mathrm{c}}^{3}\right)^{-4.08}\right], \\
\tau_{\mathrm{a}} & =\exp \left[-m \beta\left(0.6777+0.1464 m \beta-0.00626(m \beta)^{2}\right)^{-1.3}\right], \\
m= & 1 /\left[\sin h+0.15(57.296 h+3.885)^{-1.253}\right], \\
m_{\mathrm{c}} & =m p_{\mathrm{s}} / p_{0},
\end{aligned}
$$

where $\tau_{\mathrm{oz}}, \tau_{\mathrm{w}}, \tau_{\mathrm{g}}, \tau_{\mathrm{r}}$, and $\tau_{\mathrm{a}}$ are the radiative transmittance due to ozone absorption, water vapour absorption, permanent gas absorption, Rayleigh scattering, and aerosol extinction, respectively. $m$ is the air mass, $m_{\mathrm{c}}$ the pressure-corrected air mass, $h$ (radian) the solar elevation, $p_{\mathrm{s}}$ surface pressure (given by equation 21) and $p_{0}=1.013 \times 10^{5} \mathrm{~Pa} . l$ is the thickness of the ozone layer (unit $\mathrm{cm}$ or 1000 Dobson Units), $\beta$ Ångström turbidity coefficient. $w$ is the precipitable water defined as the amount of water in a vertical column of atmosphere. Humidity profile measurements of the atmosphere are needed in order to calculate the precipitable water, which is usually unavailable at surface meteorological stations. In this model, the precipitable water $w(\mathrm{~cm})$ is estimated from surface relative humidity $\mathrm{RH}(\%)$ and air temperature $T(\mathrm{~K})$ by a semi-empirical formula (Yang et al., 2006):

$w=0.00493 \mathrm{RH} T^{-1} \exp \left(26.23-5416 T^{-1}\right)$.

The ozone optical depth used in this study was computed using the determinations of total ozone columnar concentration from data obtained NASA/ GSFC Ozone Processing Team. 


\section{Appendix B}

\section{Diffuse and reflected solar radiation}

Diffuse solar radiation $\left(I_{\mathrm{d}}\right)$ was calculated using the method suggested by Gates (1980):

$I_{\mathrm{d}}=I_{0} \tau_{\mathrm{d}}(\cos s)^{2} /(2 \sin a)$,

where $\tau_{\mathrm{d}}$ is the diffuse radiation transmissivity. $a$ is the solar altitude angle. $s$ is the tilt angle of the surface (slope).

$\sin a=\sin L \sin \delta_{\mathrm{s}}+\cos L \cos \delta_{\mathrm{s}} \cos h_{\mathrm{s}}$,

$L$ is the latitude, solar declination $\left(\delta_{\mathrm{S}}\right)$ and hour angle $\left(h_{\mathrm{S}}\right)$.

The equation of $\tau_{\mathrm{d}}$ in Yang et al. (2006) was used:

$\tau_{\mathrm{d}} \approx \max \left\{0,0.5\left[\tau_{\mathrm{oz}} \tau_{\mathrm{g}} \tau_{\mathrm{w}}\left(1-\tau_{\mathrm{a}} \tau_{\mathrm{r}}\right)+0.013\right]\right\}$.

The magnitude of reflected radiation depends on the slope of the surface and the ground reflectance coefficient. The reflected radiation here is the ground-reflected radiation, both direct sunlight and diffuse skylight, impinging on the slope after being reflected from other surfaces visible above the slope's local horizon. The reflecting surfaces are considered to be Lambertian. Here reflected radiation $\left(I_{\mathrm{r}}\right)$ was calculated based on the method of Gates (1980):

$I_{\mathrm{r}}=r I_{0} \tau_{\mathrm{r}}(\sin s)^{2} /(2 \sin a)$,

where $r$ is the ground reflectance. $s$ is slope. $a$ is the solar altitude angle. $\tau_{\mathrm{r}}$ is the reflected radiation transmissivity. $\tau_{\mathrm{r}}$ can be related to $\tau_{\mathrm{c}}$ by the relationship in the following equation (Kumar et al., 1997):

$\tau_{\mathrm{r}}=0.271+0.706 \tau_{\mathrm{c}}$.

\section{Appendix C}

\section{Calculation of the cosine of the solar incidence angle $(\cos \theta)$}

The solar incidence angle is the angle between the solar beam and a line perpendicular to the land surface. In the flat model, we assume that the land surface is horizontal and the calculation of $\cos \theta$ is very simple and is a constant over the area of interest. In the Mountain area, $\cos \theta$ is different for each pixel depending on the slope and aspect of the land surface. The following equations are used to $\operatorname{compute} \cos \theta$ :

$$
\begin{aligned}
\cos \theta & =\sin \delta \sin \emptyset \cos s-\sin \delta \cos \emptyset \sin s \cos \gamma \\
& +\cos \delta \cos \emptyset \cos s \cos \omega+\cos \delta \sin \emptyset \sin s \cos \gamma \cos \omega \\
& +\cos \delta \sin \emptyset \sin s \sin \omega
\end{aligned}
$$

where $\delta$ is declination of the earth (in radians, positive in summer in Northern Hemisphere).

$\delta=0.409 \sin \left[\frac{2 \pi \cdot \text { doy }}{365}-1.39\right]$ $\emptyset=$ latitude of the pixel (in radians, positive for Northern Hemisphere).

$s=$ slope (radians) where $s=0$ is horizontal and $s=\pi / 2$ is vertical downward ( $s$ is always positive and represents a downward slope in any direction).

$\gamma=$ surface aspect angle (in radians) where $\gamma=0$ for due south, $\gamma=+\pi / 2$ for east, $\gamma=-\pi / 2$ for west and $\gamma= \pm \pi$ for north.

$\omega=\pi(t-12) / 12$, hour angle (in radians). $t$ is the local standard time. $\omega=0$ at solar noon, $\omega$ is negative in morning and $\omega$ is positive in afternoon.

Acknowledgements. This paper was supported in part by the Chinese National Key Programme for Developing Basic Sciences (2010CB951701), the National Natural Science Foundation of China (41275010), Opening Fund of Key Laboratory of Land Surface Process and Climate Change in Cold and Arid Regions, CAS (LPCC201207), ESA WACMOS project, the FP7 CEOP-AEGIS and CORE-CLIMAX projects. Xuelong Chen is supported by the "CAS-KNAW Joint PhD Training Programme", The authors thank all members of QOMS/CAS for their many helps in the field observation of this research. We thank Thomas Foken for discussions on turbulent data processing and Lalit Kumar for help with their solar radiation model. We thank Tobias Biermann, and Wolfgang Babel's help with TK2 software. The authors thank the anonymous reviewers for their useful comments and suggestions to improve the manuscript.

Edited by: R. Uijlenhoet

\section{References}

Aguilar, C., Herrero, J., and Polo, M. J.: Topographic effects on solar radiation distribution in mountainous watersheds and their influence on reference evapotranspiration estimates at watershed scale, Hydrol. Earth Syst. Sci., 14, 2479-2494, doi:10.5194/hess14-2479-2010, 2010.

Anderson, M. C., Norman, J. M., Kustas, W. P., Houborg, R., Starks, P. J., and Agam, N.: A thermal-based remote sensing technique for routine mapping of land-surface carbon, water and energy fluxes from field to regional scales, Remote Sens. Environ., 112, 4227-4241, doi:10.1016/j.rse.2008.07.009, 2008.

Arnold, N. S., Rees, W. G., Hodson, A. J., and Kohler, J.: Topographic controls on the surface energy balance of a high Arctic valley glacier, J. Geophys. Res., 111, F02011, doi:10.1029/2005jf000426, 2006.

Bastiaanssen, W. G. M.: SEBAL-based sensible and latent heat fluxes in the irrigated Gediz Basin, Turkey, J. Hydrol., 229, 87100, 2000.

Bollasina, M. and Benedict, S.: The Role of the Himalayas and the Tibetan Plateau Within the Asian Monsoon System, B. Am. Meteorol. Soc., 85, 1001-1004, 2004.

Boos, W. R. and Kuang, Z.: Dominant control of the South Asian monsoon by orographic insulation versus plateau heating, Nature, 463, 218-222, doi:10.1038/nature08707, 2010.

Brunt, D.: Notes on radiation in the atmosphere, Q. J. Roy. Meteorol. Soc., 58, 389-420, doi:10.1002/qj.49705824704, 1932. 
Brutsaert, W.: On a derivable formula for long-wave radiation from clear skies, Water Resour. Res., 11, 742-744, doi:10.1029/WR011i005p00742, 1975.

Brutsaert, W.: Evaporation into the atmosphere, D. Reidel, 299 pp., 1982.

Brutsaert, W.: Aspects of bulk atmospheric boundary layer similarity under free-convective conditions, Rev. Geophys., 37, 439451, doi:10.1029/1999rg900013, 1999.

Chander, G. and Markham, B.: Revised Landsat-5 TM radiometric calibration procedures and postcalibration dynamic ranges, IEEE T. Geosci. Remote, 41, 2674-2677, doi:10.1109/tgrs.2003.818464, 2003.

Chen, X., Ma, Y., Sun, F., Li, M., and Wang, S.: The Rainy Season Character of Troposphere at Mt. Qomolangma Region, Plateau meteorology, 26, 1280-1286, 2007 (in Chinese).

Chen, X., Su, Z., Ma, Y., and Sun, F.: Analysis of land-atmosphere interactions over the north region of Mt. Qomolangma (Mt. Everest), Art. Antarct. Alpine Res., 44, 412-422, doi:10.1657/19384246-44.4.412, 2012.

Chen, X., Su, Z., Ma, Y., Yang, K., Wen, J., and Zhang, Y.: An Improvement of Roughness Height Parameterization of the Surface Energy Balance System (SEBS) over the Tibetan Plateau, J. Appl. Meteorol. Clim., 52, 607-622, doi:10.1175/jamc-d-12056.1, 2013.

Chen, Y., Yang, K., Zhou, D., Qin, J., and Guo, X.: Improving the noah land surface model in arid regions with an appropriate parameterization of the thermal roughness length, J. Hydrometeorol., 11, 995-1006, doi:10.1175/2010jhm1185.1, 2010.

Daughtry, C. S. T., Kustas, W. P., Moran, M. S., Pinter Jr., P. J., Jackson, R. D., Brown, P. W., Nichols, W. D., and Gay, L. W.: Spectral estimates of net radiation and soil heat flux, Remote Sens. Environ., 32, 111-124, doi:10.1016/0034-4257(90)90012-b, 1990.

Gao, D.: Some Heating Effects of Mt Qomolangma (Everest) on the Atmosphere, B. Am. Meteorol. Soc., 62, 560-560, 1981.

Gao, Z. Q., Liu, C. S., Gao, W., and Chang, N.-B.: A coupled remote sensing and the Surface Energy Balance with Topography Algorithm (SEBTA) to estimate actual evapotranspiration over heterogeneous terrain, Hydrol. Earth Syst. Sci., 15, 119-139, doi:10.5194/hess-15-119-2011, 2011.

Gates, D. M.: Biophysical ecology, Dover Pubns, New York: Springer-Verlag, 1980.

Gueymard, C. A.: Direct solar transmittance and irradiance predictions with broadband models. Part I: detailed theoretical performance assessment, Sol. Energy, 74, 355-379, doi:10.1016/s0038-092x(03)00195-6, 2003a.

Gueymard, C. A.: Direct solar transmittance and irradiance predictions with broadband models. Part II: validation with high-quality measurements, Sol. Energy, 74, 381-395, doi:10.1016/s0038-092x(03)00196-8, 2003b.

Immerzeel, W. W., van Beek, L. P. H., and Bierkens, M. F. P.: Climate Change Will Affect the Asian Water Towers, Science, 328, 1382-1385, doi:10.1126/science.1183188, 2010.

Iziomon, M. G., Mayer, H., and Matzarakis, A.: Downward atmospheric longwave irradiance under clear and cloudy skies: Measurement and parameterization, J. Atmos. Sol.-Terr. Phy., 65, 1107-1116, doi:10.1016/j.jastp.2003.07.007, 2003.

König-Langlo, G. and Augstein, E.: Parameterization of the downward long-wave radiation at the Earth's surface in polar regions, Meteorol. Z., H.6, 343-347, 1994.
Kimball, B. A., Idso, S. B., and Aase, J. K.: A model of thermal radiation from partly cloudy and overcast skies, Water Resour. Res., 18, 931-936, doi:10.1029/WR018i004p00931, 1982.

Kumar, L., Skidmore, A. K., and Knowles, E.: Modelling topographic variation in solar radiation in a GIS environment, Int. J. Geogr. Inf. Sci., 11, 475-497, doi:10.1080/136588197242266, 1997.

Kustas, W. P. and Daughtry, C. S. T.: Estimation of the soil heat flux/net radiation ratio from spectral data, Agr. Forest Meteorol., 49, 205-223, doi:10.1016/0168-1923(90)90033-3, 1990.

Kustas, W. P., Rango, A., and Uijlenhoet, R.: A simple energy budget algorithm for the snowmelt runoff model, Water Resour. Res., 30, 1515-1527, doi:10.1029/94wr00152, 1994.

Leckner, B.: The spectral distribution of solar radiation at the earth's surface-elements of a model, Sol. Energy, 20, 143-150, doi:10.1016/0038-092x(78)90187-1, 1978.

Liang, H., Zhang, R., Liu, J., Sun, Z., and Cheng, X.: Estimation of hourly solar radiation at the surface under cloudless conditions on the Tibetan Plateau using a simple radiation model, Adv. Atmos. Sci., 29, 675-689, doi:10.1007/s00376-012-1157-1, 2012.

Long, D., Gao, Y., and Singh, V. P.: Estimation of daily average net radiation from MODIS data and DEM over the Baiyangdian watershed in North China for clear sky days, J. Hydrol., 388, 217-233, doi:10.1016/j.jhydrol.2010.04.042, 2010.

Ma, W., Ma, Y., Li, M., Hu, Z., Zhong, L., Su, Z., Ishikawa, H., and Wang, J.: Estimating surface fluxes over the north Tibetan Plateau area with ASTER imagery, Hydrol. Earth Syst. Sci., 13, 57-67, doi:10.5194/hess-13-57-2009, 2009.

Ma, Y., Zhong, L., Su, Z., Ishikawa, H., Menenti, M., and Koike, T.: Determination of regional distributions and seasonal variations of land surface heat fluxes from Landsat-7 Enhanced Thematic Mapper data over the central Tibetan Plateau area, J. Geophys. Res., 111, D10305, doi:10.1029/2005jd006742, 2006.

Ma, Y., Kang, S., Zhu, L., Xu, B., Tian, L., and Yao, T.: Tibetan Observation and Research Platform- Atmosphere-land interaction over a heterogeneous landscape, B. Am. Meteorol. Soc., 89, 1487-1492, doi:10.1175/2008BAMS2545.1, 2008.

Ma, Y., Wang, Y., Wu, R., Hu, Z., Yang, K., Li, M., Ma, W., Zhong, L., Sun, F., Chen, X., Zhu, Z., Wang, S., and Ishikawa, H.: Recent advances on the study of atmosphere-land interaction observations on the Tibetan Plateau, Hydrol. Earth Syst. Sci., 13, 1103-1111, doi:10.5194/hess-13-1103-2009, 2009.

Ma, Y., Zhong, L., Wang, B., Ma, W., Chen, X., and Li, M.: Determination of land surface heat fluxes over heterogeneous landscape of the Tibetan Plateau by using the MODIS and in situ data, Atmos. Chem. Phys., 11, 10461-10469, doi:10.5194/acp11-10461-2011, 2011.

Markham, B. L. and Barker, J. L.: Thematic Mapper bandpass solar exoatmospheric irradiances, Int. J. Remote Sens., 8, 517-523, 1987.

Mauder, M. and Foken, T.: Documentation and instruction manual of the eddy covariance software package TK2, Bayreuth, Arbeitser-gebnisse, 2004.

McVicar, T. R., Van Niel, T. G., Li, L., Hutchinson, M. F., Mu, X., and Liu, Z.: Spatially distributing monthly reference evapotranspiration and pan evaporation considering topographic influences, J. Hydrol., 338, 196-220, doi:10.1016/j.jhydrol.2007.02.018, 2007. 
Monteith, J. L.: Principles of environmental physics, Edward Arnold Press, 1973.

Oku, Y., Ishikawa, H., and Su, Z.: Estimation of land surface heat fluxes over the Tibetan plateau using GMS data, J. Appl. Meteorol. Clim., 46, 183-195, 2007.

Prata, A. J.: A new long-wave formula for estimating downward clear-sky radiation at the surface, Q. J. Roy. Meteorol. Soc., 122, 1127-1151, doi:10.1002/qj.49712253306, 1996.

Prescott, J. A.: Evaporation from a water surface in relation to solar radiation, Trans. R. Soc. Sci. Aust., 64, 114-125, 1940.

Qin, Z., Karnieli, A., and Berliner, P.: A mono-window algorithm for retrieving land surface temperature from Landsat TM data and its application to the Israel-Egypt border region, Int. J. Remote Sens., 22, 3719-3746, doi:10.1080/01431160010006971, 2001.

Rebmann, C., Gockede, M., Foken, T., Aubinet, M., Aurela, M., Berbigier, P., Bernhofer, C., Buchmann, N., Carrara, A., Cescatti, A., Ceulemans, R., Clement, R., Elbers, J. A., Granier, A., Grunwald, T., Guyon, D., Havrankova, K., Heinesch, B., Knohl, A., Laurila, T., Longdoz, B., Marcolla, B., Markkanen, T., Miglietta, F., Moncrieff, J., Montagnani, L., Moors, E., Nardino, M., Ourcival, J. M., Rambal, S., Rannik, U., Rotenberg, E., Sedlak, P., Unterhuber, G., Vesala, T., and Yakir, D.: Quality analysis applied on eddy covariance measurements at complex forest sites using footprint modelling, Theor. Appl. Climatol., 80, 121-141, doi:10.1007/s00704-004-0095-y, 2005.

Richter, R., Kellenberger, T., and Kaufmann, H.: Comparison of Topographic Correction Methods, Remote Sensing, 1, 184-196, 2009.

Sobrino, J. A., Jiménez-Muñoz, J. C., and Paolini, L.: Land surface temperature retrieval from LANDSAT TM 5, Remote Sens. Environ., 90, 434-440, doi:10.1016/j.rse.2004.02.003, 2004.

Su, H., McCabe, M. F., Wood, E. F., Su, Z., and Prueger, J. H.: Modeling evapotranspiration during SMACEX: comparing two approaches for local- and regional-scale prediction, J. Hydrometeorol., 6, 910-922, doi:10.1175/JHM466.1, 2005.

Su, Z.: The Surface Energy Balance System (SEBS) for estimation of turbulent heat fluxes, Hydrol. Earth Syst. Sci., 6, 85-100, doi:10.5194/hess-6-85-2002, 2002.

Su, Z., Schmugge, T., Kustas, W. P., and Massman, W. J.: An evaluation of two models for estimation of the roughness height for heat transfer between the land surface and the atmosphere, J. Appl. Meteorol., 40, 1933-1951, 2001.

Teixeira, A. H. D. C.: Determining Regional Actual Evapotranspiration of Irrigated Crops and Natural Vegetation in the São Francisco River Basin (Brazil) Using Remote Sensing and PenmanMonteith Equation, Remote Sensing, 2, 1287-1319, 2010.

Tovar-Pescador, J., Pozo-Vázquez, D., Ruiz-Arias, J. A., Batlles, J., López, G., and Bosch, J. L.: On the use of the digital elevation model to estimate the solar radiation in areas of complex topography, Meteorol. Appl., 13, 279-287, doi:10.1017/s1350482706002258, 2006.

Ueno, K., Toyotsu, K., Bertolani, L., and Tartari, G.: Stepwise Onset of Monsoon Weather Observed in the Nepal Himalaya, Month. Weather Rev., 136, 2507-2522, 2008. van der Kwast, J., Timmermans, W., Gieske, A., Su, Z., Olioso, A., Jia, L., Elbers, J., Karssenberg, D., and de Jong, S.: Evaluation of the Surface Energy Balance System (SEBS) applied to ASTER imagery with flux-measurements at the SPARC 2004 site (Barrax, Spain), Hydrol. Earth Syst. Sci., 13, 1337-1347, doi:10.5194/hess-13-1337-2009, 2009.

Xie, A., Dahe, Q., Jiawen, R., Xiang, Q., Cunde, X., Shugui, H., Shichang, K., Xingguo, Y., and Youyan, J.: Meteorological observations on Mount Everest in 2005, Prog. Nat. Sci., 17, 828837, 2007.

Yang, D., Chen, H., and Lei, H.: Estimation of evapotranspiration using a remote sensing model over agricultural land in the North China Plain, Int. J. Remote Sens., 31, 3783-3798, doi:10.1080/01431161.2010.483492, 2010.

Yang, K., Huang, G. W., and Tamai, N.: A hybrid model for estimating global solar radiation, Sol. Energy, 70, 13-22, doi:10.1016/s0038-092x(00)00121-3, 2001.

Yang, K., Koike, T., Fujii, H., Tamagawa, K., and Hirose, N.: Improvement of surface flux parametrizations with a turbulencerelated length, Q. J. Roy. Meteorol. Soc., 128, 2073-2087, 2002.

Yang, K., Koike, T., and Yang, D.: Surface Flux Parameterization in the Tibetan Plateau, Bound.-Lay. Meteorol., 106, 245-262, 2003.

Yang, K., Koike, T., and Ye, B.: Improving estimation of hourly, daily, and monthly solar radiation by importing global data sets, Agr. Forest Meteorol., 137, 43-55, doi:10.1016/j.agrformet.2006.02.001, 2006.

Yang, W., Guo, X., Yao, T., Yang, K., Zhao, L., Li, S., and Zhu, M.: Summertime surface energy budget and ablation modeling in the ablation zone of a maritime Tibetan glacier, J. Geophys. Res., 116, D14116, doi:10.1029/2010jd015183, 2011.

Yang, X., Zhang, T., Qin, D., Kang, S., and Qin, X.: Characteristics and Changes in Air Temperature and Glacier's Response on the North Slope of Mt. Qomolangma (Mt. Everest), Arct. Antarct. Alpine Res., 43, 147-160, doi:10.1657/19384246-43.1.147, 2011.

Ye, D. and Gao, Y.: The meteorology of the Qinghai-1 Xizang (Tibet) Plateau, Science Press, Beijing, 1979 (in Chinese).

Zhang, W., Chen, J., Ogawa, K., and Yamaguchi, Y.: An approach to estimating evapotranspiration in the Urumqi River basin, Tianshan, China, by means of remote sensing and a geographical information system technique, Hydrol. Process., 19, 1839-1854, doi:10.1002/hyp.5639, 2005.

Zhong, L., Ma, Y., Su, Z., Lu, L., Ma, W., and Lu, Y.: LandAtmosphere Energy Transfer and Surface Boundary Layer Characteristics in the Rongbu Valley on the Northern Slope of Mt. Everest, Arct. Antarct. Alpine Res., 41, 396-405, 2009.

Zhou, L., Zou, H., Ma, S., and Li, P.: Study on impact of the South Asian summer monsoon on the down-valley wind on the northern slope of Mt. Everest, Geophys. Res. Lett., 35, L14811, doi:10.1029/2008g1034151, 2008.

Zou, H., Ma, S., Zhou, L., Li, P., and Li, A.: Measured turbulent heat transfer on the northern slope of Mt. Everest and its relation to the south Asian summer monsoon, Geophys. Res. Lett., 36, L09810, doi:10.1029/2008g1036984, 2009. 